\title{
ARTICLE
}

\section{MARSIPAN: management of really sick patients with anorexia nervosa}

\author{
Paul Robinson \& William Rhys Jones
}

Paul Robinson is an honorary research consultant psychiatrist at St Ann's Hospital, London, and a senior teaching fellow and honorary senior lecturer at University College London. His research interests are community treatment of eating disorders, severe and enduring eating disorders (SEED), management of really sick patients with anorexia nervosa (MARSIPAN) and mentalisation-based therapy in eating disorders. William Rhys Jones is a consultant psychiatrist and clinical lead at the Yorkshire Centre for Eating Disorders in Leeds. $\mathrm{He}$ is an elected member of the Faculty of Eating Disorders at the Royal College of Psychiatrists and chairs the national MARSIPAN dissemination group. His research interests include early intervention in eating disorders, severe and enduring eating disorders, dual diagnosis and family and carer interventions. Correspondence Dr Paul Robinson, Eating Disorders Service, Barnet, Enfield and Haringey Mental Health Trust, St Ann's Hospital, St Ann's Road, London N15 3TH, UK. Email: p.robinson@ucl.ac.uk

\section{Copyright and usage}

(C) The Royal College of Psychiatrists 2018

\section{SUMMARY}

Anorexia nervosa is a potentially fatal illness that affects women and a smaller proportion of men. When a patient becomes so severely ill that admission to a medical unit is required, the risk of a poor outcome is high. Most medical services do not have sufficient expertise, without psychiatric help, to manage the nutritional, medical, behavioural and family problems that often appear. These problems interact and this can adversely affect outcome. This article discusses, with reference to the MARSIPAN report, the procedure that should be followed when such a patient presents to an acute medical service. It considers diagnosis, risk assessment, consent, re-feeding syndrome, underfeeding syndrome and treatment-sabotaging behaviours. It stresses the importance of collaboration between expert medical and psychiatric staff, and involvement of the family. When these issues are adequately addressed, the outcome for the patient is more likely to be positive.

\section{LEARNING OBJECTIVES}

- Be confident in diagnosing individuals with anorexia nervosa and identify when urgent inpatient medical treatment is required

- Be confident in assessing and managing physical risk in individuals with anorexia nervosa

- Be aware of the Royal College of Psychiatrists' MARSIPAN report and its implications for the management of individuals with eating disorders in medical settings

\section{DECLARATION OF INTEREST}

None.

\section{A fictitious case}

Jane is 18 . She has done well in her exams and has secured a place at a university 200 miles from her parental home. During the summer she goes on a diet and exercises in a gym to try to get fitter for her move to university. She loses weight, but the weight loss goes out of control and she rapidly reaches a very low weight, with a BMI of only 12 . She collapses in the street while jogging and is brought to the nearest accident and emergency (A \& E) department. There she is examined by the A \& E doctor, who asks the on-call physician to see her. Her blood pressure is a bit low $(95 / 70)$, as is her pulse (44). All her bloods are normal and her electrocardiogram (ECG) shows just sinus bradycardia. The physician examines her and concludes that she can go home as long as she promises to eat more. By this time her parents have arrived and they help her leave the hospital. However, because of the weakness of her legs she is unable to walk to their car and her parents carry her back to hospital, threatening to complain if she is not admitted. She goes to a general medical admission ward where none of the staff have looked after a patient with anorexia nervosa. Finger-prick glucose measurements show low levels $(2.5 \mathrm{mmol} / \mathrm{L})$ and she refuses a glucose drink. She is given a small diet but disposes of it in the en-suite toilet. She is observed to be wiggling her toes and fingers continuously and rejects offers of food. Her parents become increasingly concerned about her. She continues to engage in micro-exercising and after 4 days is found in the toilet, unconscious. She is resuscitated with intravenous glucose. Her parents demand a psychiatric opinion and the liaison psychiatrist is called. She diagnoses anorexia nervosa and recommends cautious re-feeding, with frequent monitoring of electrolytes, especially potassium and phosphate. As Jane is resisting nutritional treatment, the psychiatrist arranges an assessment under the Mental Health Act 1983 and she is detained for treatment. Nurses trained in managing both the physical and psychological problems of patients with severe anorexia nervosa are employed to provide one-to-one care and, on nasogastric feeding, she begins to improve. The parents meet regularly with the ward staff so that they can be informed of their daughter's progress.

\section{Introduction}

Jane's case exemplifies many of the problems with which this article is concerned. Severe anorexia nervosa is uncommon, and the average medical intake unit may see perhaps two such patients a year. Hence, skills at managing the situation are often inadequate. These patients present the challenges of serious physical disorder, which can be fatal, combined with behavioural patterns that can make recovery less likely. Only a combined medical and psychiatric approach can start to address their many needs. In Jane's case, fortunately, that collaboration eventually materialised. However, in many cases it does not, and medical teams attempting to work alone can run into serious difficulties in the treatment of such a patient. There may also be reluctance on the part of psychiatric teams to engage with such a physically ill patient. However, waiting until a patient such as Jane is physically in better shape may be waiting 
too long. Her compulsion to avoid weight gain may lead to behaviours that sabotage attempts at nutritional resuscitation and repair. This is a prime example of a situation in which psychiatric and medical services working closely together can save a patient's life. In the following article, we aim to show the different physical and psychological problems presented by such patients, and how they can be addressed by collaborative work between medical and psychiatric services. For further reading the medical management of severe anorexia nervosa we recommend Birmingham \& Treasure (2010) and Robinson \& Nicholls (2015).

\section{The high mortality rate of anorexia nervosa}

Anorexia nervosa is a serious disorder which has the highest mortality of any psychiatric condition (Suokas 2013). Estimates of the death rate in anorexia nervosa vary. Steinhausen (2002), reviewing 119 studies, reported an overall mortality of $5 \%$, with an increased rate of $9.4 \%$ in studies with over 10 years follow-up. The standardised mortality ratio (SMR) is defined as 'quantifying the increase or decrease in mortality of a study cohort with respect to the general population'. Nielsen et al (1998), reviewing the literature, reported an SMR of 9.9 for females aged 20-29 with anorexia nervosa, similar to the SMR of 9.6 for anorexia nervosa in general found in a review by Hoek (2006). Nielsen et al also reported an SMR of 30 for females (all ages) in the first year after diagnosis. Emborg (1999) found that the highest SMR (14.92) was for women aged 25-29. More recently, Arcelus et al (2011) reviewed mortality literature and found an SMR of 5.86 for anorexia nervosa. This compares with SMRs of 1.91 in adult females with asthma (Ringbaek 2005) and 5.5 in females with early-onset insulin dependent diabetes mellitus (all ages) (Harjutsalo 2011). In a study of 572 out-of-hospital cardiac arrests in young adults (Deasy 2011), 1 in 200 was found to be due to anorexia nervosa.

This excess mortality appears to have a number of causes. Anorexia nervosa affects every organ system (Mehler 2015) and the heart has been found to be compromised in a high proportion of cases of severe anorexia nervosa (Sachs 2016). In the latter review, abnormalities of pericardial and valvular function, left ventricular mass and function, conduction abnormalities, low heart rate and blood pressure and dysregulation of the peripheral blood vessels were all reported. Westmoreland et al (2016), reviewing medical complications, concluded that cardiac causes, together with other medical complications and suicide, accounted for $60 \%$ of deaths in anorexia nervosa.

\section{Acute presentation of anorexia nervosa in medical settings}

The A \& E department may be the first place in which a patient with anorexia nervosa comes in contact with a healthcare professional. A review by Campbell \& Peebles (2014) demonstrated that many children and adolescents with eating disorders are undiagnosed and untreated. Consequently, they may become extremely ill and require medical admission. Once in hospital, patients with severe anorexia nervosa present major challenges. In a review of complications seen during preparation for surgery in patients with anorexia nervosa (Hirose 2014), hypoglycaemia, leukopaenia and other potentially fatal complications were seen frequently, and Gaudiani \& Mehler (2016) point to the difficulty medical units face in diagnosing and treating rare medical complications of anorexia nervosa. One potentially fatal complication in the treatment of severe anorexia nervosa is re-feeding syndrome. There are diverse views on how to avoid this condition, which usually arises in a severely ill, malnourished patient who is re-fed too rapidly. A systematic review reported that provision of calories in the initial phase of re-feeding in different services ranged from 125 to $1900 \mathrm{kcal} /$ day; the average rate of re-feeding syndrome was $14 \%$ (O'Connor 2013). Sachs et al (2015) recommend starting at $1500 \mathrm{kcal} /$ day; the NICE guideline on nutritional support for adults (National Institute for Health and Care Excellence 2006: para. 1.4.8), although stating that it does not cover patients with eating disorders, recommends $5 \mathrm{kcal} / \mathrm{kg} /$ day if the $\mathrm{BMI}$ is under 14.5 , which equates to $150 \mathrm{kcal} /$ day for a $30 \mathrm{~kg}$ patient. Despite the statement that it excludes eating disorders, this NICE guideline is nevertheless used as a guide for the treatment of anorexia nervosa in some medical units in the UK. Not surprisingly, with this extreme diversity of advice, the management of patients with anorexia nervosa in medical units raises uncertainties in the staff, and this may contribute to an adverse outcome.

\section{Addressing the problems: the MARSIPAN process}

The MARSIPAN working group arose out of concerns about the acute care of patients with severe anorexia nervosa admitted, because of rapid physical deterioration, to general medical in-patients services, usually through the A \& E department. Once in hospital, the aim of the staff will usually be to improve nutrition by means of re-feeding and this can be life-saving. However, the patient may be terrified of weight gain and resist re-feeding, even though this behaviour may well be life-threatening. It is the care of this challenging group of patients 
that the MARSIPAN report, first published in 2010 and revised in 2014 (Royal College of Psychiatrists 2014), primarily addresses. The report includes the MARSIPAN checklist (Fig. 1), an aide-mémoire for the points that require attention when a severely ill patient with anorexia nervosa is admitted to a medical unit.

\section{Diagnostic issues}

The diagnosis of anorexia nervosa is quite often known before presentation to hospital. However, a number of other conditions can mimic anorexia nervosa because body image disturbance and valuation of thinness may occur in the presence of weight loss due to physical diseases such as Crohn's disease, Addison's disease, malabsorption syndrome and various forms of malignancy, and these and other conditions must be ruled out. Medical investigations to follow up findings (such as raised liver enzymes) can divert attention from the patient's nutritional needs, which may be neglected.

\section{Treatment issues}

Treatment of patients with severe anorexia nervosa (Robinson 2015) involves attention to physical, psychological and social aspects of the disorder. These patients, fearful of weight gain, may sabotage nutritional treatment by discarding food or nasogastric feed, vomiting, taking laxatives or over-exercising. They may become depressed and suicidal and may self-harm. Family members are extremely anxious and that anxiety may lead to interventions that may not fit with the treatment programme, for example calling in a medical relative for an informal 'second opinion'. Management therefore needs to include nutritional rehabilitation, mental health nursing support, supportive psychotherapy, close psychiatric liaison and help for the family and the staff group.

\section{Deaths of patients with anorexia nervosa in medical settings}

The epidemiology of this group of patients, including the number of deaths that occur, is unknown,

\section{MARSIPAN checklist}

\section{for Really Sick Patients with Anorexia Nervosa}

\begin{tabular}{|c|c|c|}
\hline Assessing & Refeeding & Managing \\
\hline $\begin{array}{l}\text { Does the patient have anorexia } \\
\text { nervosa? }\end{array}$ & $\begin{array}{l}\text { Is intensive medical care needed? } \\
\square \quad \text { Yes }\end{array}$ & $\begin{array}{l}\text { Are medical and psychiatric staff } \\
\text { collaborating in care? }\end{array}$ \\
\hline$\square$ Yes & $\square$ No and regular risk monitoring in place & $\square$ Yes \\
\hline$\square$ Not sure and psychiatric review requested & Increased risk of refeedina & $\square$ No and psychiatric consultation awaited \\
\hline Are there significant risk factors? & syndrome? & \\
\hline $\begin{array}{l}\square \quad \mathrm{BMI}<13 \text { (adults) or }<70 \% \text { median BMl for age } \\
\text { (under 18)? }\end{array}$ & $\square$ Low initial electrolytes & $\begin{array}{l}\text { Are nurses trained in managing } \\
\text { medical and psychiatric problems? }\end{array}$ \\
\hline $\begin{array}{l}\square \text { Recent loss of } \geq 1 \mathrm{~kg} \text { for two consecutive } \\
\text { weeks? }\end{array}$ & $\begin{array}{l}\square \text { Low BMI }<13 \text { or mBMI <70\%) } \\
\square \text { Significant comorbidities (e.g. infection, }\end{array}$ & $\square$ Yes \\
\hline $\begin{array}{l}\text { Weeks? } \\
\square \text { Little or no nutrition for }>5 \text { days? }\end{array}$ & $\begin{array}{l}\text { cardiac failure, alcoholism, uncontrolled } \\
\text { diabetes) }\end{array}$ & $\begin{array}{l}\square \quad \text { No and appropriately skilled staff } \\
\text { requested/training in place }\end{array}$ \\
\hline$\square$ Acute food refusal or $<500 \mathrm{kcal} /$ day for $>2$ days & $\rightarrow$ Start at $5-10 \mathrm{kcal} / \mathrm{kg} / \mathrm{day}$ & \\
\hline $\begin{array}{l}\text { in under } 18 \mathrm{~s} \text { ? } \\
\square \text { Pulse }<40 \text { ? }\end{array}$ & $\begin{array}{l}\rightarrow \text { Monitor electrolytes twice daily and build up } \\
\text { calories swiftly: avoid underieeding }\end{array}$ & $\begin{array}{l}\text { Are there behaviours that increase } \\
\text { risk? }\end{array}$ \\
\hline$\square$ BP low with postural dizziness? & Lower risk of refeeding syndrome? & $\square$ Purging behaviours \\
\hline $\begin{array}{l}\square \text { Core temperature }<35^{\circ} \mathrm{C} \text { ? } \\
\square \mathrm{Na}<130 \mathrm{mmol} / \mathrm{L} \text { ? }\end{array}$ & $\rightarrow$ Start at $15-20 \mathrm{kcal} / \mathrm{kg} / \mathrm{day}$ and build up & $\square$ Falsifying weight \\
\hline$\square \mathrm{K}<3.0 \mathrm{mmol} / \mathrm{L}$ ? & $\begin{aligned} & \text { swiftly } \\
\rightarrow & \text { Avoid underfeedina syndrome }\end{aligned}$ & $\square$ Disposing of feed \\
\hline$\square$ Raised transaminase? & $\rightarrow$ Avoid underfeeding syndrome & $\square$ Exercising \\
\hline$\square$ Glucose $<3 \mathrm{mmol} / \mathrm{L}$ ? & Give all adults oral thiamine and & $\square$ Self-harm, suicidality \\
\hline$\square$ Raised urea or creatinine? & Pabrinex $^{\oplus}$ & $\square$ Family distress/anxiety \\
\hline$\square$ EGG: e.g. bradycardia? QTc $>450 \mathrm{~ms}$ ? & Monitor & $\square$ Safeguarding concerns \\
\hline Is the patient consenting to treatment? & $\rightarrow$ Electrolytes (especially P, K) & $\rightarrow \begin{array}{l}\text { Mobilise psychiatric team to advise on } \\
\text { management }\end{array}$ \\
\hline$\square$ Yes & $\rightarrow \mathrm{ECG}$ & \\
\hline $\begin{array}{l}\square \text { No and assessment for compulsory detention } \\
\text { requested }\end{array}$ & $\begin{array}{l}\rightarrow \text { Vital signs } \\
\rightarrow \mathrm{BMl}\end{array}$ & \\
\hline
\end{tabular}

(c) 2015 The Royal College of Psychiatrists. To request permission for republication (in print, online or by any othef medium), please write to permissions@rcpsych.ac.uk

See full report: Royal College of Psychiatrists, Royal College of Pathologists, Royal College of Physicians. MARSIPAN: Management of Really Sick Patients with Anorexia Nervosa, 2nd edition (College Report CR189). Royal College of Psychiatrists. 
and surveys of medical units are required in order to estimate the prevalence and incidence of admissions of patients with severe anorexia nervosa, and the proportion giving rise to serious management problems and a fatal outcome. A number of deaths have occurred in UK hospitals and are attributed to problems with medical or psychiatric management and particularly to shortfalls in adequate liaison between the two. It is likely that this problem, identified in the UK, is one that affects all countries in which patients with anorexia nervosa are treated in medical units.

In this article, advice is provided for front-line staff dealing with severely ill patients with anorexia nervosa. For brevity, the patient is referred to as 'she', although a significant proportion of such patients will be male.

\section{Clinical assessment of 'MARSIPAN' patients}

\section{Diagnosis}

The latest classification for eating disorders, the DSM-5 (American Psychiatric Association 2013), gives clear criteria for anorexia nervosa. These are listed in Box 1.

In a young person with a history of self-imposed weight loss, sometimes purging food by vomiting, and sometimes engaging in binge eating, the diagnosis is clear. Physical causes of weight loss such as diabetes mellitus, endocrine diseases such as thyrotoxicosis and Addison's disease, and malignant conditions should all be excluded. Treatment of the eating disorder should not be delayed while investigations for medical conditions continue. Most patients brought to A \& E departments or admitted to medical units have already received the diagnosis of anorexia nervosa.

\section{Physical examination and investigations Overview}

Assuming that the diagnosis of anorexia nervosa has been made, a patient with severe anorexia nervosa can have a large number of physical problems. Some of the most important are listed here.

- Emaciation: the patient may look cadaverous and be covered with fine downy 'lanugo' hair. She may be shivering and be found to have hypothermia (core temperature $<35^{\circ} \mathrm{C}$ ).

- Weakness: the patient may be unable to sit up or may show weakness on the sit-up/squat-stand (SUSS) test (Fig. 2).

- Bradycardia, low heart rate: a rate of less than 40 bpm, while awake, has been thought to indicate higher risk.
BOX 1 DSM-5 diagnostic criteria for anorexia nervosa

(a) Persistent restriction of energy intake leading to significantly low body weight (in context of what is minimally expected for age, sex, developmental trajectory, and physical health)

(b) Either an intense fear of gaining weight or of becoming fat, or persistent behaviour that interferes with weight gain (even though significantly low weight).

(c) Disturbance in the way one's body weight or shape is experienced, undue influence of body shape and weight on self-evaluation, or persistent lack of recognition of the seriousness of the current low body weight.

\section{Subtypes}

- Restricting type

- Binge-eating/purging type

- Postural hypotension: a large drop in blood pressure on standing, accompanied by symptoms of dizziness or faintness, indicates that the cardiovascular system is severely affected.

- Delayed gastric emptying: the stomach slows down in anorexia nervosa, and the patient can have a very dilated stomach, which occasionally can rupture if a large meal or a binge is ingested.

- Abnormal blood tests: urea and electrolyte abnormalities (Mehler 2004) are common, with hypokalaemia being the most common dangerous condition. However, sodium, urea, creatinine, magnesium and phosphate can all be dangerously abnormal. It is not unusual for transaminase levels to be elevated in an acutely ill patient with anorexia nervosa (Hanachi 2013), but apart from a rise during re-feeding, the levels generally settle with treatment, and a major search for a hepatic diagnosis is not usually warranted. Levels of haemoglobin, white cells and platelets can all be low. For further details, see the 'Blood tests' section below.

The role of body mass index (BMI)

There is no doubt that monitoring of body weight is a vital measure of risk in patients with anorexia nervosa. Non-medical personnel (e.g. psychotherapists) seeing patients with the illness need to be able to do some simple physical measures and a risk assessment based on BMI and to get medical advice if concerned. BMI is calculated as the person's weight in kilograms divided by their height in metres squared, i.e. BMI = weight $(\mathrm{kg}) /$ height $\left(\mathrm{m}^{2}\right)$. 


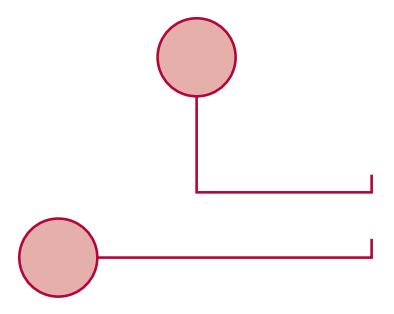

1 Sit up: patient lies down flat on the floor and sits up without, if possible, using their hands

Scoring (for sit-up and squat-stand tests separately)

0 : Unable

1: Able only using hands to help

2: Able with noticeable difficulty

3: Able with no difficulty

In adults over 18 years of age, the following ranges have been suggested for BMI risk in anorexia nervosa (Royal College of Psychiatrists 2014):

- low risk: BMI 15-17.5

- medium risk: BMI 13-15

- high risk: $\mathrm{BMI}<13$

The patient's BMI should always be worked out. However, some clinicians may have difficulty, even with a calculator, and Table 1 may help.

In addition to its diagnostic value in eating disorders, BMI is a proxy measure of medical risk and demonstrates a U-shaped curve when measured against all-cause mortality, with increased mortality rates noted at a low $(<20)$ and high $(>35)$ BMI (Prospective Studies Collaboration 2009).

BMI, however, has its limitations as a risk measure since it can easily be manipulated by fluid-loading and hiding weights in one's clothing, and efforts should be made to minimise and control for such behaviours where possible. Likewise, BMI does not account for differences in muscle:fat ratio, meaning that men in most cases have a higher level of physical risk for each BMI range compared with women. BMI is also less reliable in the following circumstances:

- extremes of height

- children and adolescents

- rapid changes in weight

- regular bulimic behaviour

- physical comorbidity

- pregnancy.

With this in mind, it is important to remember that BMI should always be interpreted in the context of the clinical history and physical examination and that it is not the only measure of physical risk in low-weight patients.

It should be appreciated, though, that patients are fully aware that they risk going to hospital if their BMI is low, and they may go to remarkable lengths to avoid that admission, because it may mean weight gain. Some patients drink copious amounts of water before weighing. In one case, known to one of us (P. R.), a woman who was being treated as an out-patient had an epileptic fit, which was found to be related to severe hyponatraemia (119 mmol/L). She was unconscious for several days and her weight in hospital was $9 \mathrm{~kg}$ lower than at her last out-patient appointment, a few days before, suggesting that she had drunk 9 litres of water before weighing. After she woke up she had confided that she had been placing a shower rose in her mouth and turning on the shower to fill her stomach. Other attempts to increase weight include placing objects under clothes and inserting coins into the vagina. Hence, other approaches to assessing risk need to be adopted. Some involve physical investigations and are discussed below. Others require observation and simple testing.

\section{Monitoring muscle power}

As weight goes down, muscle weakness develops and this is likely to be a sign of severe under-nutrition (Box 2).

In the clinic you may wish to observe whether the patient has any difficulty with stairs, or with getting up from a chair. More formally, clinicians can ask the patient to perform the SUSS test (Fig. 2). The patient is asked to lie down flat and sit up, then to squat and stand, without, if possible, using their hands. The test has a simple scoring scale and it can be charted during a clinic visit.

\section{Blood tests}

Blood tests (Mehler 2004) are not uncommonly within normal ranges in anorexia nervosa (Table 2). Oddly, this can be dangerous, because some physicians, seeing normal biochemistry in a patient who has been admitted to hospital, assume that it is safe to discharge the patient even if BMI and muscle power indicate severe malnutrition. One patient with a low BMI was discharged from a medical ward. She was able to walk along the pavement, but when she reached a kerb, thigh weakness prevented her from raising her foot to step up. She fell and was readmitted after a formal complaint by her parents. The lesson is that normal biochemistry does not always mean low risk.

However, the following blood tests can be abnormal in anorexia nervosa and this may increase the risk of death. 


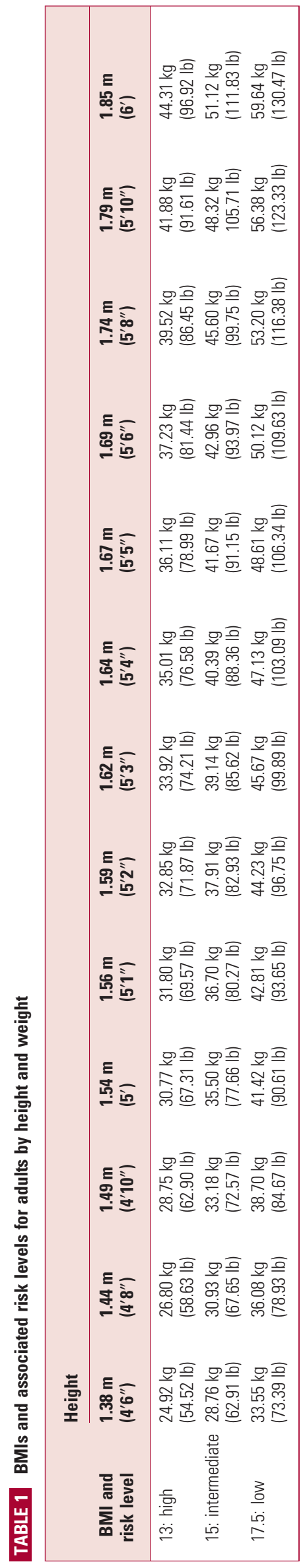

BOX 2 Breakfast in bed

A woman with anorexia nervosa was being seen as an outpatient. Her weight was gradually falling. When her BMI fell below 13 , her legs became significantly weak. She was in the habit of bringing her mother breakfast in bed each morning. As her weight fell, she became unable to walk up the stairs with the tray, so she would place it on a stair then drag herself, seated, up the stairs one at a time, moving the tray stair by stair ahead of her until she reached her mother's bedroom.

\section{Electrolytes}

Hypokalaemia (low potassium) may be due to vomiting or laxative misuse. In hypokalaemia due to vomiting, potassium levels fall not mainly because of gastric loss of potassium cations $\mathrm{K}^{+}$, which is minimal, but because of loss of hydrogen ions $\mathrm{H}^{+}$. The resulting alkalosis is resisted by the kidneys, which exchange $\mathrm{H}^{+}$for $\mathrm{K}^{+}$. This helps lower the $\mathrm{pH}$, but potassium is lost. Most potassium is intracellular and a reduced serum level suggests a profound body deficit.

Sodium may be reduced as a result of waterloading to falsify weight.

Urea and creatinine may be raised owing to kidney failure, which can develop because of dehydration (some patients restrict fluids as well as calories) and chronic hypokalaemia, which damages the kidneys. A patient with a normal urea level and virtually no protein intake may in fact have renal impairment, masked by low production of urea.

\section{Other blood tests}

Creatine kinase (CK), an enzyme contained in skeletal and cardiac muscle, can be released, leading to raised blood levels. Expect the levels to increase when the patient exercises. This can be one sign of covert exercise. Both skeletal (CK-MM) and cardiac (CK-MB) isomers may be raised, although this has not been shown to correlate with cardiac damage in anorexia nervosa.

Tests of liver function, such as alanine transaminase (ALT) and aspartate aminotransferase (AST) levels can be raised. The cause of this is unknown, but it may be a sign of auto-digestion in the starving state. It is commonly seen in severe anorexia nervosa and reverses during re-nutrition, sometimes after an initial increase when nutrition begins. Liver failure is very rare, although there is a danger that liver disease may be pursued, at the expense of refeeding the patient. The effects of liver biopsy in a physically frail individual can be serious and biopsy is not usually indicated. 
TABLE 2 Some of the laboratory abnormalities seen in severe anorexia nervosa

\begin{tabular}{|c|c|c|c|c|}
\hline Test & Change & Cause & Effect & Treatment \\
\hline Potassium & Low & $\begin{array}{l}\text { Vomiting: } \mathrm{H}^{+} \text {retained and } \mathrm{K}^{+} \text {lost in } \\
\text { kidney due to alakalosis. Laxatives: } \mathrm{K}^{+} \\
\text {lost in stools. }\end{array}$ & Cardiac arrhythmias & $\begin{array}{l}\text { Reduce vomiting, or laxatives. Give } \\
\text { oral or occasionally IV } \mathrm{K}^{+} \text {. Proton } \\
\text { pump inhibitor. }\end{array}$ \\
\hline Sodium & Low & Water-loading & Fits & Reduce water intake \\
\hline Urea & Low & Low protein intake & Nil & None \\
\hline Creatinine & Raised & Dietary, or renal dysfunction & Effects of renal dysfunction & Rehydration, treat renal problem \\
\hline Magnesium & Low & Laxative misuse & $\begin{array}{l}\text { Hypokalaemia, } \\
\text { hypocalcaemia, arrhythmia }\end{array}$ & $\begin{array}{l}\text { Reduce laxatives, give magnesium } \\
\text { salts (oral, IV) }\end{array}$ \\
\hline Phosphate & Low & $\begin{array}{l}\text { Too rapid re-feeding (re-feeding } \\
\text { syndrome) }\end{array}$ & $\begin{array}{l}\text { Muscle weakness (including } \\
\text { cardiac), confusion, coma }\end{array}$ & $\begin{array}{l}\text { Reduce rate of re-feeding, give oral/ } \\
\text { IV phosphate }\end{array}$ \\
\hline $\begin{array}{l}\text { Liver } \\
\text { None. Small } \\
\text { risk of } \\
\text { hepatic } \\
\text { failure }\end{array}$ & $\begin{array}{l}\text { Wait. } \\
\text { Possibly } \\
\text { reduce } \\
\text { rate of } \\
\text { re- } \\
\text { feeding } \\
\text { if major } \\
\text { rise. }\end{array}$ & enzymes & High & Hepatocyte auto-digestion? \\
\hline Blood count & Low & $\begin{array}{l}\text { Gelatinous transformation of the } \\
\text { marrow }\end{array}$ & Infections, purpura & Haematology consultation \\
\hline
\end{tabular}

$\mathrm{H}^{+}$, hydrogen ions; IV, intravenous; $\mathrm{K}^{+}$, potassium cations

In bone marrow dysfunction associated with anorexia nervosa, the haemoglobin level is often low (e.g. $100 \mathrm{~g} / \mathrm{L})$, but not dangerously so. Other cell lines can also be reduced and occasionally pancytopaenia is observed, with low white cell, red cell and platelet counts. This is due to gelatinous degeneration of the bone marrow (Zhao 2017) and can present with skin haemorrhages due to a low platelet count.

\section{Electrocardiogram (ECGs)}

The ECG is quite often abnormal in anorexia nervosa. It is thought that QTc interval prolongation (i.e. $>450 \mathrm{~ms}$ ) may be a precursor of sudden death in anorexia nervosa, and for this reason it is regarded as a high-risk finding. Typically, the QTc interval
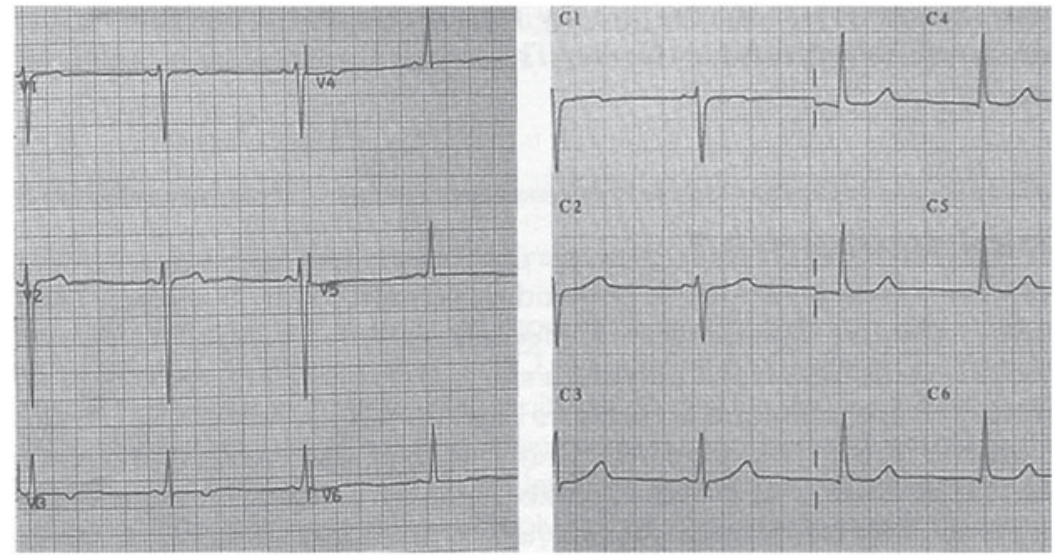

Electrocardiograms before (left) and after (right) re-feeding. The left-hand trace shows T-wave inversion in V3 and V4 and flattening in V5-6. These abnormalities reversed with re-feeding (Robinson 2006: p. 68). (C) John Wiley and Sons. With permission. increases as weight decreases and improves with weight gain. Clinicians should therefore be cautious when prescribing any medication associated with QTc prolongation (e.g. antipsychotics) in lowweight patients. Other findings reported in severe anorexia nervosa that respond to weight gain are slowing of the heart rate (bradycardia) and decreased left ventricular mass (Mont 2003), as well as T-wave flattening, which can mimic the ECG appearance in angina or a heart attack (Fig. 3).

\section{Mental state examination}

A severely ill patient with anorexia nervosa can present a complex mental state. Although the patient may seem to be alert and to understand her situation, she may paradoxically deny that her life is in danger but say that she would rather die than put on weight. The patient may hide food, get rid of feed being provided via a nasogastric tube, and over-exercise. One type of exercising that can be hard for staff to manage has been termed 'microexercising' (Robinson 2006). The patient may be lying in bed, but is observed to be continually moving toes and fingers. Insisting on standing up is another variant of this and patients have been known to do so for over $24 \mathrm{~h}$. Micro-exercising can be particularly dangerous when the patient is very emaciated, because it can be accompanied by hypoglycaemia (Mayo Clinic 2015), which occurs because carbohydrate stores (glycogen in liver and muscle) become entirely exhausted due to negligible intake associated with exercise. 


\section{Capacity}

One question that is frequently asked in the case of patients with severe anorexia nervosa is 'Does the patient have the capacity to make treatment decisions?' This question must be answered for any patient receiving care and it can be quite complex (Tan et al, 2015). Decision-making capacity is assessed using the Mental Capacity Act 2005, and four elements are tested. The British Medical Association (BMA) has published a framework and 'toolkit' to help the practical assessment of capacity (British Medical Association 2016). The four elements are as follows.

1 Can the patient understand the information relevant to the decision? Usually, in the case of anorexia nervosa, the answer is yes, the patient can understand, for example, how severe underweight threatens her life. However, sometimes a patient will deny the threat to her life, and she may strongly disagree with the doctor about the severity of her condition, in which case the answer to this question may be no, she cannot understand the information relevant to the decision.

2 Can the patient retain the information? Unless she has serious brain damage, a patient with anorexia nervosa is generally able to retain the relevant information. As a test, she can be asked to repeat it after $5 \mathrm{~min}$.

3 Can the patient use or weigh the information? Adequate testing of this aspect of capacity requires training and experience. It is the element often failed by patients with severe anorexia nervosa. The patient can understand that her physical state leads to serious risks to life and health, but her fear of weight gain leads her to refuse treatment, such as nutritional rehabilitation, because she does not want to gain weight, even though her BMI may be dangerously low. The Mental Capacity Act Code of Practice makes this point: 'For example, a person with the eating disorder anorexia nervosa may understand information about the consequences of not eating. But their compulsion not to eat might be too strong for them to ignore' (Department for Constitutional Affairs 2007: para. 4.22).

4 Can the patient communicate the decision she wishes to make? Almost always, a patient with anorexia nervosa can communicate her decision verbally.

Capacity can only be assessed for a particular decision at a particular time. Capacity can fluctuate and vary depending on the intervention being proposed. A person may have capacity to agree to a blood test, but not to a nasogastric feed. The intervention must be specified: in anorexia nervosa, it may for example be the passage of a nasogastric tube, or transfer to a specialist eating disorders unit (SEDU). The date and time that capacity is assessed must be recorded in the patient's record, and the capacity assessment is valid only for that decision at that time.

\section{The family}

The admission of a son or daughter to a medical unit for treatment of severe anorexia nervosa is extremely stressful for the family. If the patient seems to be sabotaging treatment or does not improve, the stress escalates. The NICE guideline on eating disorders (National Collaborating Centre for Mental Health 2017) recommends that families and carers should always be involved in treatment. Moreover, in the case of patients with severe anorexia nervosa being admitted to medical wards, the MARSIPAN guidance (Royal College of Psychiatrists 2014) recommends that:

- family members should always be involved in care; if an adult patient refuses to allow information to be passed to the family, family members can still be seen and counselled without divulging private information about the patient;

- meetings should be held between a family member, senior members of the medical and psychiatric team and, if appropriate, the patient in order to explain the situation and its evolution and to answer questions;

- if the patient is treated compulsorily, contact with the next of kin is mandatory;

- in rare cases in which family members might try to sabotage treatment, they can be excluded from the care of an adult patient.

\section{Multidisciplinary treatment of patients with severe anorexia nervosa}

\section{Problems facing the medical teams}

Severe anorexia nervosa presents very difficult medical and psychiatric problems to the treating team. Hence, a team that is lacking one set of skills or the other cannot provide an effective service. How to deal with a falling phosphate level in a patient being re-fed is a medical question. How to approach the problem of micro-exercising or refusal to accept life-saving treatment requires psychiatric skills. The team therefore requires physicians, psychiatrists, medical nurses and mental health nurses, dietitians, preferably including one with experience of managing anorexia nervosa, and, if possible, a psychologist experienced in treating the disorder. This is one situation in which a comprehensive multidisciplinary approach can be life-saving. The team needs to meet soon after the patient's admission 
and then at regular intervals. Hospitals in which few patients with anorexia nervosa are admitted face a difficult problem: how to make sure that, when such a patient does arrive, she receives expert treatment. One possible solution to this dilemma is to establish, for every hospital, a 'pop-up MARSIPAN team' (Royal College of Psychiatrists 2014). This comprises a physician, a psychiatrist, a general nurse, a psychiatric nurse, a dietitian and a manager (and any other interested professional) who have had MARSIPAN training and are ready to advise a treating team at the hospital, should an patient with anorexia nervosa be admitted.

\section{Nutrition}

Patients with severe anorexia nervosa will have a number of medical problems, and investigations will reveal which organs and systems are affected. The principles of resuscitation and repair of the severely malnourished state are given in the MARSIPAN guidance (Royal College of Psychiatrists 2014). Nutrition of these patients is complicated and is addressed below, but first we wish to address the management of the behavioural and psychological problems that can lead to nutrition being sabotaged.

\section{Management of behavioural and psychological problems}

The treatment of a patient with severe anorexia nervosa involves striking a balance between trust and suspicion (on both sides). Unless the patient has trust in the staff providing care, she is unlikely to improve. She will very likely suspect (rightly) that the aim of the staff is to improve her nutrition, which she is vehemently against. However, she may also be aware that the staff are intent on saving her life, and this is usually something she does want. On the side of the staff, trust cannot be assumed, and staff will be aware that the patient may be behaving in ways that sabotage weight gain. Nevertheless, it is usually not helpful to assume that everything the patient says is false. Again, a balance needs to be struck, and that is not simple or easy, mainly because the real situation (e.g. whether the patient is actually sabotaging her recovery) is not certain. Letting the patient know about the dilemma you face is sometimes quite helpful, and staff can also convey the idea that they understand that the behaviours the patient is exhibiting are driven by irresistible compulsion (rather than wilful badness). Some physical measures can give a clue that the patient is in the grip of a treatment-sabotaging behaviour. These include hyponatraemia (due to water-loading), hypokalaemia (due to vomiting or laxative misuse) and falling scores on the SUSS test when the BMI is rising or staying stable.

Box 3 gives a list of systemic precautions that can be taken in this difficult situation.

\section{Compulsory treatment}

Here there is a cultural difference between specialties. Psychiatrists are quite used to their patients refusing essential treatment and to using the laws governing involuntary treatment (e.g. section 12 of the Mental Health Act 1983 in England and Wales). In contrast, physicians, faced with an intelligent and articulate patient, may be very reluctant to ask for a Mental Health Act assessment. From the physician's point of view, if treatment is refused then treatment is not given. The support of the psychiatric team may be required in order to suggest, and sometimes insist, that if the patient is judged not to have capacity to refuse treatment then compulsion under mental health legislation such as the Mental Health Act may need to be considered, to save the patient's life. This can be the case in severe anorexia nervosa. The tests for applying the Mental Health Act to detain a patient for assessment and compulsory treatment are that, in the opinion of two doctors, one a psychiatrist, supported by an approved mental health professional:

1 the person is suffering from a mental disorder

2 and that this is of a nature or to a degree that, despite her refusal to go to hospital, she ought to be detained in hospital in the interests of her own health, her safety or for the protection of others.

BOX 3 Precautions to follow in order to avoid and deal with sabotaging behaviours

- If weight gain is less than expected, suspect treatmentsabotaging behaviours

- Arrange an early meeting between medical and psychiatric staff to decide on a management plan, including regular follow-up meetings

- Involve a nutrition team, if one is available

- Involve the patient (and, almost always, the family) in initial and follow-up discussions about the treatment plan

- Arrange to train nurses, including those providing one-toone care, as soon as they arrive on the ward

- Write a clear care plan to be handed over between shifts

- Arrange follow-up meetings of both medical and psychiatric staff at least once a week, more if the situation demands

- Be prepared to use a compulsory treatment order (e.g. under the Mental Health Act) if necessary 
These two criteria can apply to anorexia nervosa, which is recognised to be a mental disorder and, when severe, can cause the death of the sufferer. It should be appreciated that, under the 2007 amendments to the Mental Health Act, the doctor in charge of treatment, formerly called the responsible medical officer and now called the responsible clinician, must have generalised training in the use of the Act and also be approved under section 12 of the Act to conduct such assessments. It would be rare for a treating physician who is not a psychiatrist to have such approval, and therefore, in practice, physicians can no longer fulfil the role they used to fulfil (as responsible medical officers) before the Mental Health Act was amended.

Sometimes clinicians encounter the opinion that a patient with anorexia nervosa cannot be treated compulsorily because she does not have a psychotic disorder. This is wrong and the Mental Health Act Commission (1999) cleared up the matter. It stated that anorexia nervosa is a mental disorder and hence someone with the condition can be subject to compulsory admission under the Mental Health Act in appropriate circumstances. It also gave the opinion that feeding is treatment for the eating disorder and hence can, if necessary, be given against the patient's will. Compulsory feeding may be given under section 63 of the Mental Health Act (Department of Health 2015; Curtice 2016), which covers treatments that have been directed by the approved clinician (the health professional in overall charge of the treatment), but to which the patient has not consented.

Thiels (2008, 2009) suggested that compulsory admission should be contemplated for a patient who is not cooperating with treatment when the $\mathrm{BMI}$ is $<13$. Thiels also points out that compulsory feeding might contravene Article 3 of the Human Rights Act 1998 (as the European Convention on Human Rights is currently enacted in the UK): 'No one shall be subjected to torture or to inhumane treatment or punishment'. The patients themselves, however, in general endorse the idea that in some circumstances, compulsory treatment may be required to save life and, in those circumstances, should be provided (Tan et al, 2010).

\section{Witholding treatment}

Under two circumstances the treating team may consider not providing treatment. First, if it appears that treatment is extremely unlikely to improve the patient's quality of life, the team may regard treatment as futile. This is a major decision, and the team, the patient, the family and an independent opinion all need to be involved. Second, a patient may have signed an advance directive when in a better state, indicating their wish not to have treatment should they become ill again. This is also fraught with legal and ethical difficulty and sometimes turns on whether the patient is judged to have had capacity when they signed the advance directive. These difficult issues are discussed by Tan $\mathcal{E}$ Richards (2015).

\section{Re-feeding a patient with severe anorexia nervosa}

The route and rate of re-feeding are critical decisions. Oral re-feeding is preferable, as it avoids a difficult transition from the enteral to oral route, and it probably has a lower risk of inducing re-feeding syndrome. However, some patients refuse oral feeds, and the decision then is whether to feed the patient orally under legal compulsion, a process that is very difficult to do, or feed enterally using a

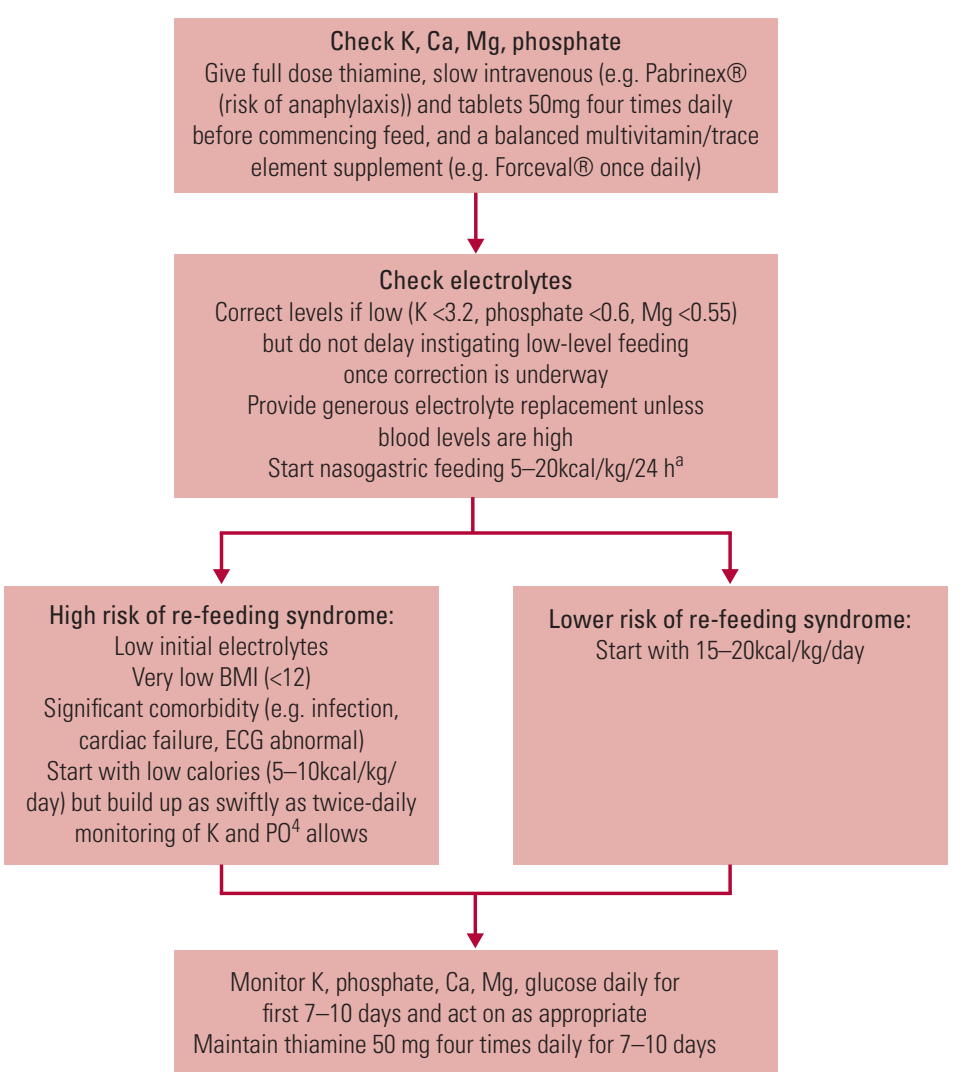

a. First $24 \mathrm{~h}$, limit calorie intake to between 5 and $20 \mathrm{kcal} / \mathrm{kg} / \mathrm{day}$, depending on clinical risk factors. For initial feeding at over $15 \mathrm{kcal} / \mathrm{kg} /$ day, increase energy intake by $10-20 \%$ every 2-3 days until basal metabolic requirement (BMR) intake is achieved.

If low initial calorie levels are used (5-15 kcal $/ \mathrm{kg} /$ day), clinical and biochemical review should be twice daily with calories increased in steps to $20 \mathrm{kcal} / \mathrm{kg} / \mathrm{per}$ day within 2 days unless there is a contraindication.

Once BMR intake is established and the patient is physically stable, it is recommended that $10 \%$ is added if bed-bound and 15-20\% if mobile. Once this is achieved, an extra $400 \mathrm{kcal}$ can be added to facilitate weight gain. Careful monitoring of blood glucose is essential during this period.

Note that hypoglycaemia, pyrexia or hypothermia, and either a rise or fall in white blood count, may indicate hidden infection rather than lack of food.

Flowchart for re-feeding patients with severe anorexia nervosa (Royal College of Psychiatrists 2014). 
nasogastric tube. The rate of re-feeding varies according to where the patient is being treated. In a specialised eating disorder unit (SEDU), refeeding syndrome with a calorie intake of $20 \mathrm{kcal} /$ $\mathrm{kg} /$ day is very rare. However, patients on a medical ward are likely to have risk factors known to predispose them to re-feeding syndrome:

- very low BMI $(<13)$

- electrolyte or renal abnormalities prior to refeeding

- infection

- other serious medical problems (e.g. cardiac failure, hepatic failure with major elevation of liver enzymes).

In those situations, it may be decided to give calories at a lower rate, $5-10 \mathrm{kcal} / \mathrm{kg} /$ day. However, it mustbe recognised that this rate is very low (e.g. $150 \mathrm{kcal} /$ day for a patient weighing $30 \mathrm{~kg}$ ) and carries the risk of underfeeding. This has been termed underfeeding syndrome and has resulted in a number of deaths. The MARSIPAN group of physicians and psychiatrists advise that, when this low rate is used, electrolytes should be measured every $12 \mathrm{~h}$ and intake increased in steps to $20 \mathrm{kcal} / \mathrm{kg} /$ day within 2 days, unless there is a contraindication such as severe re-feeding syndrome (Royal College of Psychiatrists 2014). This process is illustrated in Fig. 4.

\section{Psychological support}

A very sick patient with severe anorexia nervosa is experiencing an extremely frightening time, and the urge to lose weight driven by her eating disorder will sometimes be combined with a fear of death and a wish to be discharged from the general hospital ward. She may also be subject to a compulsory treatment order, which presents other stresses, and her relationship with her family may be difficult. One member of the team should be available to spend some time with her regularly, daily if possible, to give her time to express some of these emotions and for the team member to convey messages from the patient to the team. If, as is often the case, the person supporting her is a junior medical nurse, then that nurse must also be supported and their reports about the patient fed through to the rest of the clinical team. Often, nursing reports are not read by more senior team members, and valuable information is lost (Box 4). The family also needs support. It is often helpful to invite carers, for example parents, to attend a meeting with the whole team and encourage them to ask questions.

\section{Psychotropic medication}

Medicating a very sick patient with anorexia nervosa is often difficult. The patient may be very
BOX 4 The importance of reading nursing reports and case notes

A young woman with anorexia nervosa was admitted to a psychiatric ward after gaining over $5 \mathrm{~kg}$ in a few days on a medical ward, probably from intravenous rehydration. Her BMl went from 12.5 to 15 . She told the nurses that she was feeling desperate about weight gain in hospital and that she just wanted to get out so she could go back on her limited diet and lose the weight she had gained. She also said that she felt fat as a pig and would rather die than remain at this weight. All this was written in the case notes. In hospital she was losing weight and developed hypoglycaemia, but insisted on leaving. At a Mental Health Act assessment, the psychiatrist, who made no reference to the nursing notes, concluded (wrongly) that, as she had full mental capacity, there were no grounds to treat her against her will. She was discharged with inadequate support and died from malnutrition within a week.

agitated, and treatment with a small oral dose of a benzodiazepine (lorazepam 0.5-1 mg) or an antipsychotic (olanzapine $2.5-5 \mathrm{mg}$ ) can be beneficial. It has been suggested that olanzapine has potential to augment weight gain in anorexia nervosa (Jensen 2000). However, a number of trials and a meta-analysis (Dold 2015) have not supported its use. For more extreme agitation, for example when a very underweight patient is fighting the insertion of a nasogastric tube, the use of parenteral medication can be dangerous, because in such a patient even a small dose of a benzodiazepine can cause fatal hypotension or apnoea. The advice given in the MARSIPAN report is to treat such a patient in a medical intensive care setting, so that cardiovascular and respiratory support can be given if required (Royal College of Psychiatrists 2014).

\section{Further work required in this clinical area}

The Royal College of Psychiatrists is interested in collating anecdotes and surveys in this area. Please send information to the first author (P. R.). An online discussion forum for conferring on these issues can be accessed by sending a request to MARSIPAN-request@jiscmail.ac.uk.

\section{Conclusions}

Anorexia nervosa is a life-threatening condition that defies the dualism that has so pervaded health-care that mental and physical conditions are dealt with by different organisations, often in different buildings. Very sick patients with severe anorexia nervosa challenge these dysfunctional arrangements and only when medical and psychiatric teams work closely can the manifold problems of these patients 
be adequately addressed. Since first publication of the MARSIPAN report in 2010, there is some evidence that such cooperation has begun to happen. We advocate strongly that this process should continue, so that patients with severe anorexia nervosa can be treated in an efficient, coordinated and sympathetic way.

\section{References}

American Psychiatric Association (2013) Diagnostic and Statistical Manual of Mental Disorders (5th edn) (DSM-5). APA.

Arcelus J, Mitchell AJ, Wales J, et al (2011) Mortality rates in patients with anorexia nervosa and other eating disorders. A meta-analysis of 36 studies. Archives of General Psychiatry, 68: 724-31.

Birmingham CL, Treasure J (2010) Medical Management of Eating Disorders. Cambridge University Press.

British Medical Association (2016) Mental capacity tool kit. BMA (https:// www.bma.org.uk/advice/employment/ethics/mental-capacity/mental-cap acity-toolkit). Accessed 18 November 2017.

Campbell K, Peebles R (2014) Eating disorders in children and adolescents: state of the art review. Pediatrics, 134: 582-92.

Curtice M, James L (2016) Faith, ethics and Section 63 of the Mental Health Act 1983. BJPsych Bulletin, 40: 77-81.

Deasy C, Bray JE, Smith K, et al (2011) Out-of-hospital cardiac arrests in young adults in Melbourne, Australia - adding coronial data to a cardiac arrest registry. Resuscitation, 82: 1302-6.

Department for Constitutional Affairs (2007) Mental Capacity Act 2005: Code of Practice. TSO (The Stationery Office.

Department of Health (2015) Mental Health Act 1983: Code of Practice. Department of Health.

Dold M, Aigner M, Klabunde M, et al (2015) Second-generation antipsychotic drugs in anorexia nervosa: a meta-analysis of randomized controlled trials. Psychotherapy and Psychosomatics, 84: 110-6.

Emborg C (1999) Mortality and causes of death in eating disorders in Denmark 1970-1993: a case register study. International Journal of Eating Disorders, 25: 243-51.

Gaudiani JL, Mehler PS (2016) Rare medical manifestations of severe restricting and purging: "Zebras," missed diagnoses, and best practices. International Journal of Eating Disorders, 49: 331-44.

Hanachi M, Melchior JC, Crenn P (2013) Hypertransaminasemia in severely malnourished adult anorexia nervosa patients: risk factors and evolution under enteral nutrition. Clinical Nutrition, 32: 391-5.

Harjutsalo V, Forsblom C, Groop PH (2011) Time trends in mortality in patients with type 1 diabetes: nationwide population based cohort study. BMJ, 343: d5364.

Hirose K, Hirose M, Tanaka K, et al (2014) Perioperative management of severe anorexia nervosa. British Journal of Anaesthesia, 112: $246-54$

Hoek HW (2006) Incidence, prevalence and mortality of anorexia nervosa and other eating disorders. Current Opinion in Psychiatry, 19: 389-94.

Jensen VS, Mejlhede A (2000) Anorexia nervosa: treatment with olanzapine. British Journal of Psychiatry, 177: 87.

Mayo Clinic (2015) Hypoglycemia: causes. Mayoclinic.org (http://www. mayoclinic.org/diseases-conditions/hypoglycemia/basics/causes/con-2002 1103). Accessed 18 November 2017.

Mehler PS, Crews C, Weiner K (2004) Bulimia: medical complications. Journal of Women's Health, 13: 668-75.

Mehler PS, Brown C (2015) Anorexia nervosa - medical complications. Journal of Eating Disorders, 3: 11
Mental Health Act Commission (2004) Guidance on the Treatment of Anorexia Nervosa under the Mental Health Act 1983. MHAC (available at http://www.seedeatingdisorders.org.uk/pdfs/user/F3774357-49CE5BCB-F9BB-22ECC4C430E5.pdf).

Mont L, Castro J, Herreros B, et al (2003) Reversibility of cardiac abnormalities in adolescents with anorexia nervosa after weight recovery. Journal of the American Academy of Child and Adolescent Psychiatry, 42: 808-13.

National Collaborating Centre for Mental Health (2017) Eating disorders: recognition and treatment (https://www.nice.org.uk/guidance/ng69). Accessed 8/12/17

National Institute for Health and Care Excellence (2006) Nutrition Support for Adults: Oral Nutrition Support, Enteral Tube Feeding and Parenteral Nutrition (CG32). NICE.

Nielsen S, Moller-Madsen S, Isager T, et al (1998) Standardized mortality in eating disorders - a quantitative summary of previously published and new evidence. Journal of Psychosomatic Research, 44: 413-34.

O'Connor G, Nicholls D (2013) Refeeding hypophosphatemia in adolescents with anorexia nervosa: a systematic review. Nutrition in Clinical Practice, 28: 358-64.

Prospective Studies Collaboration (2009) Body-mass index and cause-specific mortality in 900000 adults: collaborative analyses of 57 prospective studies. Lancet, 373: 1083-96.

Ringbaek T, Seersholm N, Viskum K (2005) Standardised mortality rates in females and males with COPD and asthma. European Respiratory Journal, 25: 891-5.

Robinson PH (2006) Community Treatment of Eating Disorders. John Wiley \& Sons.

Robinson PH (2012) Avoiding deaths in hospital from anorexia nervosa: the MARSIPAN project. Psychiatrist, 36: 109-13.

Robinson PH, Nicholls D (2015) Critical Care for Anorexia Nervosa: The MARSIPAN Guidelines in Practice. Springer.

Royal College of Psychiatrists, Royal College Physicians, Royal College of Pathologists (2014) MARSIPAN: Management of Really Sick Patients with Anorexia Nervosa (2nd edn) (College Report CR189). Royal College of Psychiatrists.

Sachs K, Andersen D, Sommer J, et al (2015) Avoiding medical complications during the refeeding of patients with anorexia nervosa. Eating Disorders, 23: 411-21

Sachs KV, Harnke B, Mehler PS, et al (2016) Cardiovascular complications of anorexia nervosa: a systematic review. International Journal of Eating Disorders, 49: 238-48.

Steinhausen HC (2002) The outcome of anorexia nervosa in the 20th century. American Journal of Psychiatry, 159: 1284-93.

Suokas JT, Suvisaari JM, Gissler M, et al (2013) Mortality in eating disorders: a follow-up study of adult eating disorder patients treated in tertiary care, 1995-2010. Psychiatry Research, 210: 1101-6.

Tan J0, Stewart A, Fitzpatrick R, et al (2010) Attitudes of patients with anorexia nervosa to compulsory treatment and coercion. International Journal of Law and Psychiatry, 33: 13-19.

Tan J, Richards L (2015) Legal and ethical issues in the treatment of really sick patients with Anorexia Nervosa. In Critical Care for Anorexia Nervosa (eds P Robinson, D Nicholls). Springer.

Thiels C (2008) Forced treatment of patients with anorexia. Current Opinion in Psychiatry, 21: 495-8.

Thiels C. Curtice MJR (2009) Forced treatment of anorexic patients: part 2. Current Opinion in Psychiatry, 22: 497-500.

Westmoreland P, Krantz MJ, Mehler PS (2016) Medical complications of anorexia nervosa and bulimia. American Journal of Medicine, 129: 30-7.

Zhao X (2017) Gelatinous transformation. PathologyOutlines.com website (http://www.pathologyoutlines.com/topic/bonemarrowseroustransformation.html). Accessed 18 November 2017.
MCO answers

$1 \mathrm{~b} \quad 2 \mathrm{~d} \quad 3 \mathrm{c} \quad 4 \mathrm{c} \quad 5 \mathrm{~b}$ 


\section{MCOs}

Select the single best option for each question stem

An 18-year-old patient near death with severe anorexia nervosa is seen in the $A \& E$ department. Her $\mathrm{BMI}$ is 9.6 and she is unable to sit up. She has signs of infection in her chest and her liver function is mildly abnormal. Her breathing is normal, 15 breaths per minute, her pulse is 48 , blood pressure 95/70. ECG shows QTC at the upper limit of normal. A nasogastric tube is passed but she pulls it out within $30 \mathrm{~min}$. She is seen to wiggle her toes continuously.

1 How should treatment be managed?

a The physicians get on with managing the acute illness and involve psychiatry when the patient is sitting up.

b Medical and psychiatric staff are all involved from the outset.

c The patient should be moved to ICU and managed there, initially.

d The patient should be moved to a specialist eating disorders unit immediately.

e As the hospital has no expertise in managing anorexia nervosa, she should be transferred elsewhere.
2 Treatment against her will seems necessary. Under what legal framework should it be done?

a Under Common Law for the first $48 \mathrm{~h}$.

b Using the Mental Capacity Act.

c Using the Mental Health Act, with the consultant physician as responsible clinician.

d Using the Mental Health Act, with a liaison psychiatry consultant as responsible clinician.

e Using the consent of the next of kin who has a lasting power of attorney for health and welfare decisions.

3 A nasogastric tube is passed. What would be the most appropriate initial re-feeding regime?

a $1800 \mathrm{kcal}$ per day.

b Wait for chest infection to clear before giving nutrition

c $5-10 \mathrm{kcal} / \mathrm{kg} /$ day, increasing after $12-24 \mathrm{~h}$.

d $5-10 \mathrm{kcal} / \mathrm{kg} /$ day, increasing after 5 days.

e $20 \mathrm{kcal} / \mathrm{kg} /$ day with regular bloods to detect refeeding syndrome.
4 With regard to the use of psychotropic medication in very sick patients with severe anorexia nervosa:

a parenteral administration of psychotropic medication should never be used

b benzodiazepines should only be considered in patients who are resisting nasogastric feeding

c atypical antipsychotics could be considered as a means of managing distress and agitation

d medication should always be seen as the first line of management if the patient is distressed

e MARSIPAN recommends that antidepressants should be stopped during nasogastric feeding.

5 How should her abnormal liver function tests be managed?

a Refer for specialist hepatology opinion.

b Monitor liver function tests expecting them to rise during re-feeding and then falling to normal levels in time.

c Slow rate of re-feeding until liver function tests are normal.

d Order a liver ultrasound and isotope scan.

e Assume a paracetamol overdose and give $\mathrm{N}$ acetyl cysteine as a precaution. 